\title{
Polysaccharide Films Built by Simultaneous or Alternate Spray: A Rapid Way to Engineer Biomaterial Surfaces
}

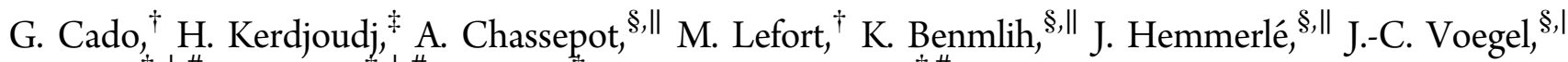 \\ L. Jierry, ${ }^{\dagger, \perp, \#}$ P. Schaaf, ${ }^{f, \perp, \#}$ Y. Frère, ${ }^{\dagger}$ and F. Boulmedais, ${ }^{*, t, \#}$
}

${ }^{\dagger}$ Centre National de la Recherche Scientifique, Institut Charles Sadron, UPR 22, 23 rue du Loess, 67034 Strasbourg Cedex, France

${ }^{\ddagger}$ UFR Odontologie, EA 4691, SFR-Cap-Santé, Université de Reims, 1 rue du Maréchal Juin, 51095 Reims Cedex, France

${ }^{\S}$ Institut National de la Santé et de la Recherche Médicale (INSERM, UMR 977), 11 rue Humann, 67085 Strasbourg Cedex, France

"Université de Strasbourg, Faculté de Chirurgie Dentaire, 1 place de l'Hôpital, 67000 Strasbourg Cedex, France

${ }^{\perp}$ Université de Strasbourg, Ecole Européenne de Chimie, Polymères et Matériaux, 25 rue Becquerel, 67087 Strasbourg Cedex, France

${ }^{\#}$ International Center for Frontier Research in Chemistry, 8 allée Gaspard Monge, 67083 Strasbourg Cedex, France

\section{Supporting Information}

\begin{abstract}
We investigated polysaccharide films obtained by simultaneous and alternate spraying of a chitosan ( $\mathrm{CHI}$ ) solution as polycation and hyaluronic acid (HA), alginate (ALG), and chondroitin sulfate (CS) solutions as polyanions. For simultaneous spraying, the film thickness increases linearly with the cumulative spraying time and passes through a maximum for polyanion/CHI molar charge ratios lying between 0.6 and 1.2. The size of polyanion/CHI complexes formed in solution was compared with the simultaneously sprayed film growth rate as a function of the polyanion/CHI molar charge ratio. A good correlation was found. This suggests the importance of polyanion/polycation complexation in the simultaneous spraying

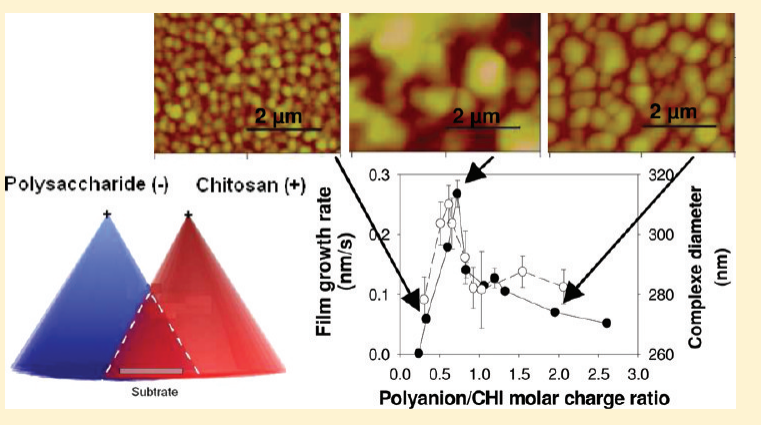
process. Depending on the system, the film topography is either liquid-like or granular. Film biocompatibility was evaluated using human gingival fibroblasts. A small or no difference is observed in cell viability and adhesion between the two deposition processes. The $\mathrm{CHI} / \mathrm{HA}$ system appears to be the best for cell adhesion inducing the clustering of CD44, a cell surface HA receptor, at the membrane of cells. Simultaneous or alternate spraying of $\mathrm{CHI} / \mathrm{HA}$ appears thus to be a convenient and fast procedure for biomaterial surface modifications.
\end{abstract}

\section{INTRODUCTION}

Glycosaminoglycans, chondroitin sulfate, heparin, and hyaluronic acid constitute the most important polysaccharides in mammalian tissue. Polysaccharides possess specific properties used in biomedical applications. ${ }^{1}$ Specific saccharide sequences activate or inhibit growth factors, act as ligands for cell surface receptors or organize the nanoscale structure of the extra cellular matrix (ECM). ${ }^{1}$ Biocompatibility of biomedical devices toward the biological environment are largely driven by the surface properties of the implant. ${ }^{2,3}$ Surface functionalization constitutes a major issue that has attracted large interest especially for the control of interfacial interactions between materials and adsorbing biological molecules. ${ }^{4-6}$ Among physical surface modification, the layer-by-layer (LbL) deposition of polyelectrolyte multilayers, introduced in the 1990s, ${ }^{7}$ became a popular tool for functionalization of biomaterials by polysaccharides as antifouling coatings, ${ }^{8,9}$ to induce low adhesion of primary cells $\mathrm{s}^{10,11}$ and of bacteria ${ }^{12,13}$ or to reduce platelet adhesion. ${ }^{14,15}$ PEMs built with polysaccharides were also used as delivery systems of osteoinductive proteins (rhBMP-2 $)^{16}$ or growth factors. ${ }^{17}$ Yet, the sequential process of the LbL method realized by dipping is time-consuming.
During the past decade, improvements have been made to turn the LbL method in a more user-friendly and faster deposition process. First introduced by Schlenoff et al., ${ }^{18}$ the alternate spraying of polyanion and polycation solutions has gained interest. ${ }^{19-21}$ Recently, it was shown that film buildup can be obtained not only by alternate, but also by simultaneous spraying of interacting polyanions and polycations. ${ }^{22,23}$

In this paper, we investigated thin coatings of polysaccharides to modify biomaterial surfaces focusing on alternate and simultaneous spraying processes that can be used on a wide range of substrates. We focus our attention on three polyacids, hyaluronic acid (HA), alginate (ALG), and chondroitin sulfate (CS), and a polybase, chitosan ( $\mathrm{CHI}$ ), to prepare the coatings. The formula of the corresponding monomers is given in Figure 1. Coatings realized with $\mathrm{CHI} / \mathrm{HA}, \mathrm{CHI} / \mathrm{ALG}$, and $\mathrm{CHI} / \mathrm{CS}$ were studied by following their buildup by ellipsometry and by characterizing their topography by atomic force microscopy. The influence of the polyanion/CHI molar charge ratio, $\mathrm{pH}$,

Received: February 7, 2012

Revised: $\quad$ May 2, 2012

Published: May 3, 2012 
$\mathbf{a}$

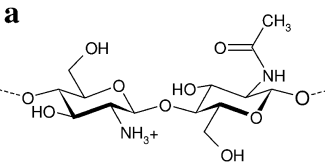

c

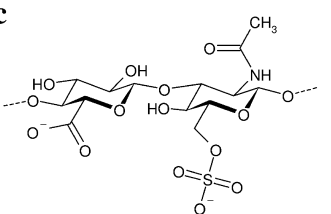

Figure 1. Monomers of polysaccharides employed (a) chitosan, (b) hyaluronic acid, (c) chondroitin sulfate, and (d) alginate.

and salt concentration was investigated. Their biocompatibility and the immunocytochemical properties were evaluated using human gingival fibroblasts (HGFs) as model system.

\section{MATERIALS AND METHODS}

Polysaccharide Solutions. Chondroitin sulfate sodium salt from shark cartilage (CS, $\sim 70000 \mathrm{~g} / \mathrm{mol}$ ) was purchased from SigmaAldrich, PROTASAN Ultrapure Chitosan Cl 213 (CHI, $260000 \mathrm{~g} /$ mol, DA 83\%) was purchased from Novamatrix, Dried Sodium Hyaluronate (HA, $420000 \mathrm{~g} / \mathrm{mol}$ ) was purchased from Lifecore Biomedical. Alginic acid sodium salt (ALG, very low viscosity, $\sim 70000$ $\mathrm{g} / \mathrm{mol}$ ) was obtained from Alfa Aesar. Poly(ethylene imine) (PEI, 70 $000 \mathrm{~g} / \mathrm{mol}, 50 \mathrm{w} \%$ in water), sodium chloride, sodium dodecyl sulfate (SDS), $\mathrm{HCl}$, and $\mathrm{NaOH}$ were purchased from Sigma. All products were used without further purification. Polyelectrolyte solutions were prepared by dissolution of adequate amounts in $150 \mathrm{mM} \mathrm{NaCl}$ aqueous solution prepared using ultrapure Milli- $\mathrm{Q}$ water having a resistivity of $18.2 \mathrm{M} \Omega . \mathrm{cm}$. All the polyelectrolyte solutions were adjusted at $\mathrm{pH} 4$ with $\mathrm{NaOH}$ or $\mathrm{HCl}$ solutions. The $\mathrm{CHI}$ solutions were prepared at $0.3 \mathrm{mg} / \mathrm{mL}\left(1.5 \times 10^{-3} \mathrm{~mol} / \mathrm{mL}\right.$ in monomer $)$, whereas HA, ALG, and CS were prepared in the $0.1-1 \mathrm{mg} / \mathrm{mL}$ range.

Substrate Preparation. Before use, the silicon wafers (WaferNet Inc., San José, USA) were first rinsed extensively with ethanol, and then with ultrapure water (Milli-Q), and, if necessary, dried under air stream. They were treated for $3 \mathrm{~min}$ in a plasma cleaning device at medium power (Harrick Plasma, Ithaca, New-York, USA). The treatment started after $1 \mathrm{~min}$ so that the appropriate vacuum was reached. Glass substrates were cleaned in a SDS solution at $10^{-2} \mathrm{M}$, ultrasonicated during $5 \mathrm{~min}$, and then submitted to a hot $0.1 \mathrm{M} \mathrm{HCl}$ solution during $10 \mathrm{~min}$ and finally rinsed with ultrapure Milli-Q water.

Simultaneous and alternate Spraying Buildup. An automated spraying device was used for simultaneous and alternate deposition of polysaccharides. This device is constituted by four identical Airbrushes VL (Paasche, USA) nozzles, each pressurized by in-house compressed nitrogen line under a pressure of 2 bar and connected to solenoid valves. The spraying of the different solutions, following a chosen deposition sequence, is obtained by a succession of closings and openings of the valves controlled by homemade software. Three nozzles allow spraying of the polycation, the polyanion, and the rinsing solutions. The fourth nozzle, free of solution, is used for the drying step. The substrate is mounted vertically on a mobile holder. To avoid patterns and to avoid gravity effects, the substrate is rotated at $150 \mathrm{rpm}$ and moved vertically at a speed of $4 \mathrm{~cm} / \mathrm{s}$. For simultaneous spraying experiments, polycation and polyanion solutions were sprayed simultaneously during $5 \mathrm{~s}$ followed by a rinsing step of $5 \mathrm{~s}$ with Milli-Q Water ( $\mathrm{pH}$ 5.9) and a drying step of $15 \mathrm{~s}$ under a nitrogen stream of 2 bar. The buildup time, denoted as cumulative spraying time, corresponds to the total duration of simultaneous spraying of the polysaccharide solutions. In the alternate spraying process, polycation and polyanion solutions were sprayed alternatively during $5 \mathrm{~s}$ separated by rinsing steps of $5 \mathrm{~s}$ with Milli-Q Water (pH 5.9) followed by a drying step with a stream of nitrogen at 2 bar during 15 s. Here, the cumulative spraying time corresponds to the total duration of spraying of both polysaccharide solutions. The charge ratio of the sprayed polysaccharides, i.e., polyanion/polycation, is defined as the ratio of the molar charge spraying rates of the polyanion and polycation, expressed in moles of charges in monomer per second calculated from the solution spraying rate $(\mathrm{mL} / \mathrm{s})$ and the concentration of each polysaccharide. The charge ratio of sprayed polysaccharides was varied by changing the concentration of the polysaccharides in the solutions while keeping the spraying rate of the solutions constant. The solution spraying rates were $14 \pm 2 \mathrm{~mL} / \mathrm{min}$ for both positively and negatively charged polysaccharides. The surface coating growth rates are expressed in nanometer per second $(\mathrm{nm} / \mathrm{s})$.

Ellipsometry. Measurements of the film thickness were carried out with a PLASMOS SD 2300 ellipsometer (PLASMOS GmbH, München, Germany) operating at the single wavelength of $632.8 \mathrm{~nm}$ and a constant angle of $70^{\circ}$. Due to the inherent limitation of ellipsometry to determine simultaneously the refractive index and the film thickness for very thin films, the refractive index of all the deposited coatings was assumed to be constant and fixed at $n=1.465$. While this procedure could lead to incorrect values in the absolute film thicknesses, it allows for a quick and precise determination of relative values. The measurements were performed after drying the deposited material under a stream of air or nitrogen. For each studied substrate, thickness measurements were randomly performed on ten different domains over an area of $1 \mathrm{~cm}^{2}$ of the film surface.

Atomic Force Microscopy (AFM). Atomic force microscopy measurements were realized with a Veeco Multimode Nanoscope IIIA (Digital Instrument). All AFM images, deflection and height, were acquired in contact mode in the dry state and in the wet state using cantilevers of silicon nitride (model MSCTAUHW, Veeco, CA) with a spring constant of $0.6 \mathrm{~N} / \mathrm{m}$.

Dynamic Light Scattering (DLS). The size measurements, i.e., the average diameter, of polysaccharide complexes were performed by dynamic light-scattering with a Zetasizer Nano ZS (Malvern, U.K.). All the measurements were performed at $25{ }^{\circ} \mathrm{C}$ with an angle of $173^{\circ}$. To obtain polysaccharide complex solutions of different polyanion/ polycation monomer molar ratios, a solution of polyanions at a fixed concentration was added in one shot to a CHI solution at $0.3 \mathrm{mg} / \mathrm{mL}$, i.e., $1.51 \times 10^{-3} \mathrm{~mol} / \mathrm{mL}$ in monomer. After $1 \mathrm{~min}$ under stirring, polysaccharide complexes were filtered on $0.45 \mu \mathrm{m}$ pores Rotilabo, and the DLS measurement was performed.

Biocompatibility of Multilayer Films. Human gingival fibroblasts (HGFs) were extracted from human gingival connective tissue of healthy individuals according to a protocol approved by the ethics committee for patient protection of CPP Strasbourg Hospitals. Cells were grown in DMEM containing $1 \mathrm{~g} / \mathrm{L}$ of glucose and supplemented with $10 \%$ fetal bovine serum and $100 \mathrm{IU} / \mathrm{mL}$ penicillin-streptomycin (all from Gibco). Cells were cultured at $37{ }^{\circ} \mathrm{C}$ in $5 \% \mathrm{CO}_{2}$ in $75 \mathrm{~cm}^{2}$ flasks. HGF were used between the sixth and the ninth passage. Before cell seeding, glass coverslips $(\varnothing=14 \mathrm{~mm})$ coated with different architectures were irradiated by UV for $15 \mathrm{~min}$. Then, HGFs were seeded at $3 \times 10^{4}$ cells per $\mathrm{cm}^{2}$ and cultivated at $37{ }^{\circ} \mathrm{C}$ under a $5 \%$ $\mathrm{CO}_{2}$ humidified atmosphere for different culture times (Day 1, Day 2, and Day 7).

Viability Assay. Cell viability was assessed by Alamar Blue assay (Biosource International). This assay is based on the reduction of the blue, nonfluorescent resazurin dye to the pink and fluorescent resorufin dye by living cells. ${ }^{24}$ The overall conversion rate is proportional to the metabolic activity of living cells. ${ }^{25}$ Viability was assessed for different times (Day 1, Day 2, and Day 7). After rinsing, cells with PBS, $10 \%$ reagent in complete medium were incubated for 2 h. After incubation, optical density (OD) at 570 and $630 \mathrm{~nm}$ was determined with a microplate reader. The percentage of reduction of Alamar Blue was calculated according to the procedure provided by the manufacturer. The experiments were repeated at least three times for each film type.

Immunocytochemical Detection of Collagen Type I and Cytoskeleton F-Actin. Cells were fixed with 3.7\% paraformaldehyde for $15 \mathrm{~min}$ at room temperature, permeabilized in $0.25 \%$ Triton X-100 in phosphate buffer solution (PBS) for $10 \mathrm{~min}$, and blocked in $1 \%$ BSA-PBS (BSA: bovine serum albumin) for $30 \mathrm{~min}$. Thereafter, cells 

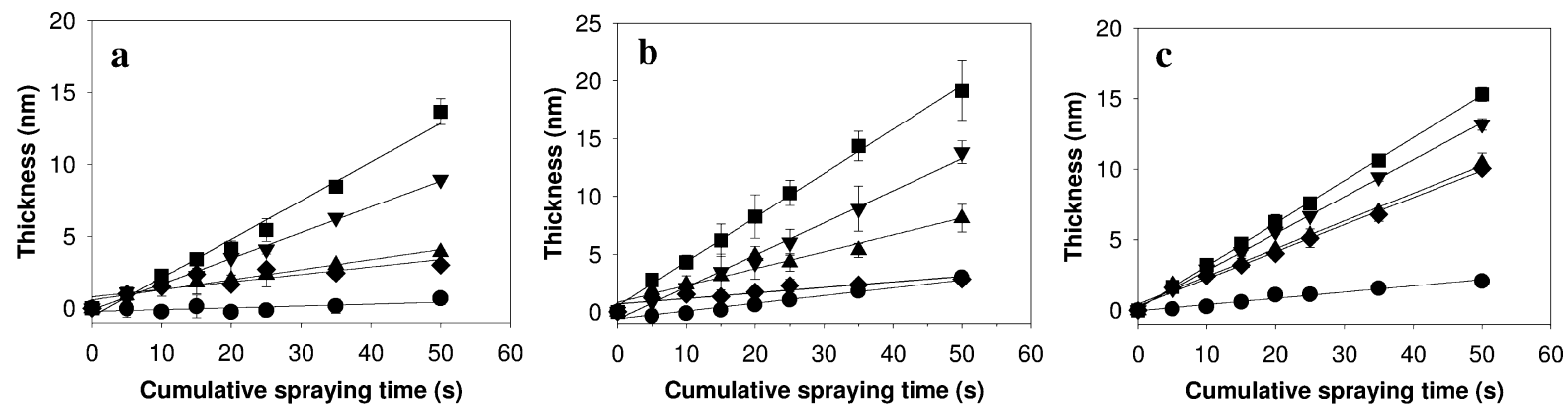

Figure 2. Thickness of polysaccharide films built, in $150 \mathrm{mM} \mathrm{NaCl}$ solution at $\mathrm{pH} 4$, by simultaneous spraying as a function of the cumulative spraying time for (a) CHI/HA system with a constant CHI spraying rate of $(2.5 \pm 0.4) \times 10^{-4} \mathrm{~mol} / \mathrm{s}$ and for different $[\mathrm{HA}] /[\mathrm{CHI}] \mathrm{molar}$ charge ratios: $(\bullet) 0.24,(\boldsymbol{\nabla}) 0.60,(\boldsymbol{\square}) 0.73,(\boldsymbol{\Delta}) 1.96$, and (\$) 2.61; (b) CHI/ALG with a constant CHI spraying rate of $(3.6 \pm 0.2) \times 10^{-4} \mathrm{~mol} / \mathrm{s}$ and for

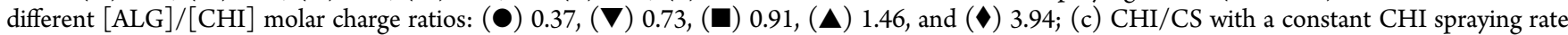
of $(3.7 \pm 0.2) \times 10^{-4} \mathrm{~mol} / \mathrm{s}$ and for different $[\mathrm{CS}] /[\mathrm{CHI}]$ molar charge ratios: $(\boldsymbol{\bullet}) 0.3,(\boldsymbol{\nabla}) 1.08,(\boldsymbol{\square}) 1.26,(\boldsymbol{\Delta}) 2.42$, and $(\boldsymbol{\nabla}) 3.23$. The data represent the mean and standard deviation of two independent measurements.
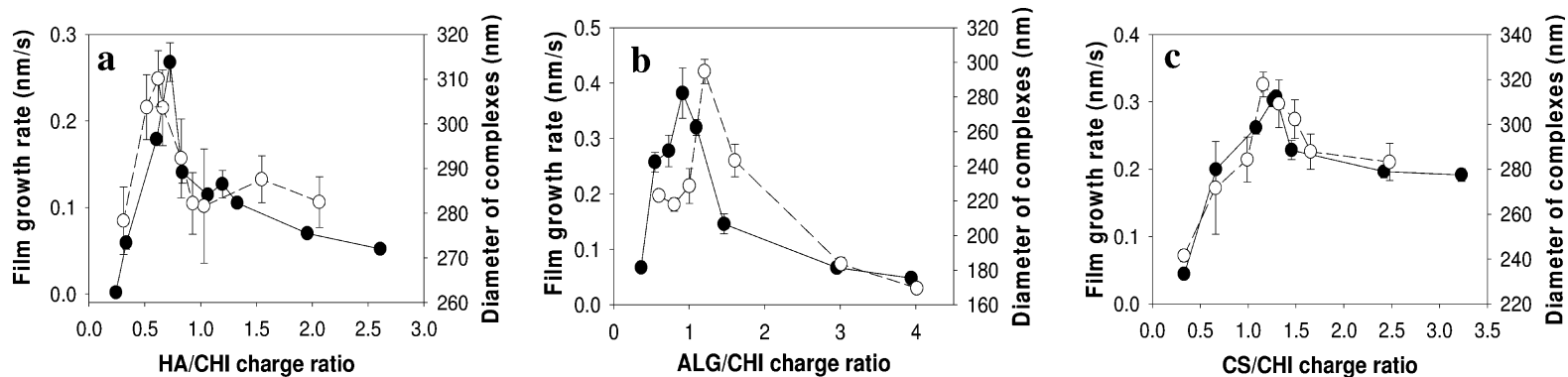

Figure 3. (O) Growth rate of polysaccharides films obtained by simultaneous spraying and $(O)$ average diameter of polysaccharide complexes as a function of the polyanion/polycation charge ratio for (a) CHI/HA, (b) CHI/ALG, and (c) CHI/CS system solubilized in $150 \mathrm{mM} \mathrm{NaCl}$ and pH 4. The simultaneous spraying of $\mathrm{CHI} / \mathrm{HA}, \mathrm{CHI} / \mathrm{ALG}$, and $\mathrm{CHI} / \mathrm{CS}$ system was done with a constant $\mathrm{CHI}$ spraying rate of $(2.5 \pm 0.4) \times 10^{-4},(3.6 \pm$ $0.2) \times 10^{-4}$, and $(3.7 \pm 0.2) \times 10^{-4} \mathrm{~mol} / \mathrm{s}$, respectively. Polysaccharide complexes were obtained by one-shot addition of the polyanion in $0.3 \mathrm{mg} /$ $\mathrm{mL}$ CHI solution. The data represent the mean and the standard deviation of two independent measurements.

were incubated at room temperature for $2 \mathrm{~h}$ with rabbit anticollagen type I (COL1) antibody (Ab-cam), at the dilution of $1 / 200$. After $3 \mathrm{~h}$, COL1 incubated slides were extensively washed with PBS and a secondary antibody (Invitrogen Alexa fluor antirabbit IgG) was added at a dilution of $1 / 1000$ and incubated for $2 \mathrm{~h}$ at room temperature in the dark. For cytoskeleton visualization, HGFs were incubated for 30 $\mathrm{min}$ at room temperature in the dark with $5 \times 10^{-5} \mathrm{mg} / \mathrm{mL}$ phalloidin-tetramethyl rhodamine B isothiocyanate (Sigma-Aldrich). Nuclear counterstaining with DAPI $(50 \mathrm{ng} / \mathrm{mL})$ (Invitrogen) was performed at room temperature for $1 \mathrm{~min}$. Washed slides were mounted on blades with fluorescent mounting medium (DAKO, Trappes, France), and fluorescence distribution was examined by means of an inverse fluorescence microscope (Axiovert, Zeiss, Le Pecq, France).

Immunostaining of CD44 Membrane Receptor. HGFs were washed twice with PBS and blocked in 1\% BSA-PBS for $30 \mathrm{~min}$. CD44 monoclonal antibody coupled with fluorescein isothiocyanate at the dilution of $1 / 50$ was incubated for $1 \mathrm{~h} 30 \mathrm{~min}$ at $37^{\circ} \mathrm{C}$ in the dark. Cells were washed with PBS, fixed with $4 \%$ paraformaldehyde, and mounted.

Statistical Analysis. The data were expressed as mean \pm standard deviation of the mean for each condition. Each experiment was repeated independently three times in triplicate. Mean values were compared with one-way ANOVA using the software SigmaPlot in which $p$ represents the rejection level of the null hypothesis of equal means. When the null hypothesis could be rejected, pairwise multiple comparisons were performed (using the Shapiro-Wilk test).

\section{RESULTS AND DISCUSSION}

Buildup of Polysaccharide Coatings by Simultaneous or Alternate Spraying. We first investigated the evolution of the thickness of films built by simultaneous spraying of polyanions and polycations as a function of the cumulative spraying time. The evolution of their thickness, measured by ellipsometry for different polyanion concentration (HA, ALG, and $\mathrm{CS}$ ) varying in the range $0.1-1 \mathrm{mg} / \mathrm{mL}$ keeping the $\mathrm{CHI}$ concentration constant at $0.3 \mathrm{mg} / \mathrm{mL}$, is shown in Figure 2a-c. The thickness increases linearly as a function of the cumulative spraying time even if the spraying rates of the polyanions and the polycations are very different. In the alternate spraying procedure, $\mathrm{CHI} / \mathrm{HA}$ film thickness grew superlinearly with the cumulative spraying time (Figure S-1a in Supporting Information, SI). CHI/HA exponential growth regime probably results from the diffusion of at least one of the species inside the film, the free molecules within the film participating in the growth regime. ${ }^{10}$ For CHI/ALG and CHI/CS films, the thickness increases linearly with the cumulative spraying time regardless of the deposition procedure (Figure $2 \mathrm{~b}, \mathrm{c}$; Figure S$1 b, c$ in SI). Next, we examined the influence of the polyanion/ $\mathrm{CHI}$ molar charge ratio on the growth rate of the films obtained by simultaneous spraying. The spraying rate of the polyanion was varied while keeping the spraying rate of $\mathrm{CHI}$ constant. As shown in Figure 3 for all systems, the growth rate increases rapidly with the charge ratios, and goes through a maximum before decreasing when the charge ratios become larger. The maximum of the film growth rate is observed for a $\mathrm{HA} / \mathrm{CHI}$ charge ratio around 0.7, a ALG/CHI charge ratio around 0.9, and a $\mathrm{CS} / \mathrm{CHI}$ charge ratio around 1.2. For the alternate deposition procedure, the spraying rate of the solution has no 
Table 1. Polyanion/CHI Molar Charge Ratio of Polysaccharide Solutions Used to Form Complexes with Their Respective Size and Used to Build Polysaccharide Films by the Simultaneous and Alternate Spraying Process with Their Respective Cumulative Spraying Time, Film Thickness, and Film Roughness

\begin{tabular}{ccclccc} 
system & polyanion/CHI molar charge ratio & complexe size $(\mathrm{nm})$ & type of spraying & cumulative spraying time $(\mathrm{s})$ & thickness $(\mathrm{nm})$ & roughness $(\mathrm{nm})$ \\
$\mathrm{CHI} / \mathrm{HA}$ & 0.6 & $310 \pm 6$ & simultaneous & 340 & $95 \pm 5$ & 36 \\
& & & alternate & 320 & $96 \pm 1$ & 20 \\
$\mathrm{CHI} / \mathrm{ALG}$ & \multirow{2}{*}{0.9} & $218 \pm 4$ & simultaneous & 240 & $91 \pm 4$ & 33 \\
& & & alternate & 520 & $91 \pm 1$ & 3 \\
$\mathrm{CHI} / \mathrm{CS}$ & \multirow{2}{*}{1.05} & $284 \pm 10$ & simultaneous & 290 & $87 \pm 8$ & 50 \\
& & & alternate & 450 & $88 \pm 2$
\end{tabular}

significant influence on the film growth rate (Figure S-1a-c in SI).

The simultaneous spraying procedure may be largely governed by the formation of complexes at or near the interface. We thus determined the size of the polysaccharide complexes obtained in solution by mixing the polyanions and the polycations at different charge ratios. For the three polysaccharide systems, the average diameter of the complexes reaches a maximum at a given polyanion/ $\mathrm{CHI}$ charge ratio (Figure 3, open symbols) depending on the polyanion used. When the CHI concentration is fixed at $1.51 \times 10^{-3} \mathrm{~mol} / \mathrm{mL}$, the largest complex diameter is found for a polyanion/CHI molar charge ratio around $0.6,1.2$, and 1.1, respectively, for the $\mathrm{CHI} / \mathrm{HA}, \mathrm{CHI} / \mathrm{ALG}$, and $\mathrm{CHI} / \mathrm{CS}$ systems. The charge ratio values, where the film growth rate and the size of the complexes are maximum, are very close. This correlation strengthens the hypothesis that for the simultaneous spraying procedure the film buildup is governed by the formation of complexes at the interface and the film growth rate is largely dependent upon the size of the complexes. In the case of the alternate spraying process, once the polyelectrolyte amount needed to compensate the electrostatic surface charges of the previous oppositely charged polyelectrolyte layer is reached, no further material is taken up. The alternate spraying process is thus independent of the molar charge ratio of the sprayed solutions.

Table 1 summarizes the cumulative spraying time of polysaccharide solutions used to obtain films of similar thicknesses $(\sim 90 \mathrm{~nm})$. To reach the same film thickness with polysaccharide solutions of identical concentration, the alternate spraying of $\mathrm{CHI} / \mathrm{HA}$ is slightly less time-consuming than the simultaneous spraying due the super linear growth of the film obtained by alternate spraying. For the CHI/ALG and $\mathrm{CHI} / \mathrm{CS}$ systems, the simultaneous spraying allows the cumulative spraying time to be reduced, respectively, by more than 2- and 1.5-fold compared to the alternate spraying. For comparison, the adsorption time by dipping is at least $5 \mathrm{~min},{ }^{26}$ but generally $15 \mathrm{~min} .{ }^{9,27-29}$ The dipping process is thus by far the most time-consuming. As was shown in Figure S-1 in SI, the alternate spraying allows the solution concentration to be reduced in polysaccharides to reach the same film thickness. It may be noticed that the alternate spraying of polysaccharides is less reagent-consuming but more time-consuming than the simultaneous spraying.

Morphologies of Polysaccharide Films. We compared the morphologies and the roughness of the films obtained by the simultaneous and alternate spraying processes. AFM images were obtained in the dry state. For the three polysaccharide systems, films were built by simultaneous spraying at a charge ratio close to the optimum of the growth rate, i.e., of 0.6 for CHI/HA, 0.9 for CHI/ALG, and 1.05 for CHI/CS films for a $\mathrm{CHI}$ spraying rate of $4.3 \times 10^{-4} \mathrm{~mol} / \mathrm{s}$ (Figure $4 \mathrm{a}, \mathrm{b}, \mathrm{c}$ ). For the
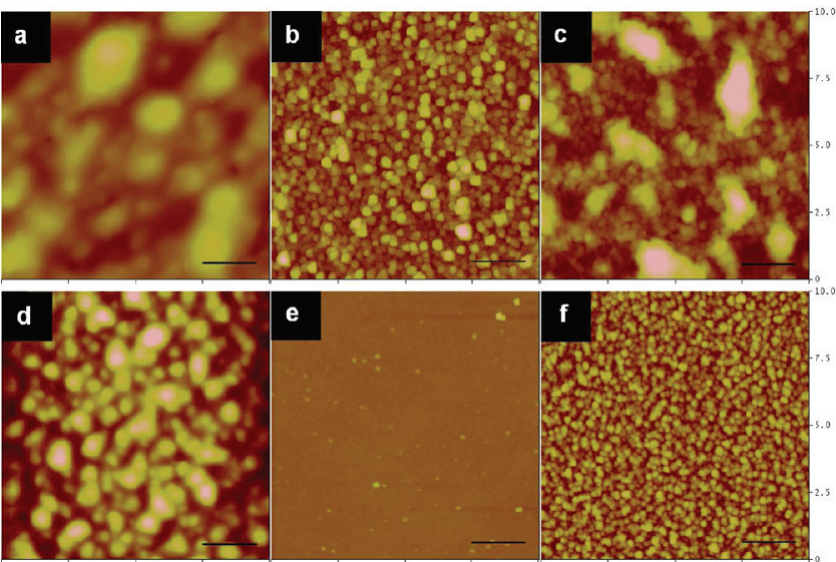

Figure 4. AFM morphology of simultaneous sprayed films (a) CHI/ $\mathrm{HA}$, (b) CHI/ALG, (c) CHI/CS; and alternate sprayed films (d) $\mathrm{CHI} / \mathrm{HA}$, (e) CHI/ALG, and (f) $\mathrm{CHI} / \mathrm{CS}$ built at $150 \mathrm{mM} \mathrm{NaCl}$ and $\mathrm{pH} 4$, at the maximum of the film growth rate with a CHI spraying rate of $4.3 \times 10^{-4} \mathrm{~mol} / \mathrm{s}$. The films were built to reach comparable thicknesses $(\sim 90 \mathrm{~nm})$. See Table 1 for experimental details. The $(x, y)$ scale bar represent $2 \mu \mathrm{m}$ and the $z$ scale is $300 \mathrm{~nm}$ for $a, b$, and $c$, and $200 \mathrm{~nm}$ for $d, e$, and $f$.

early buildup stages of the films, the substrate is only partially coated. As the buildup proceeds, the film grows in thickness and finally covers the entire surface (Figures S-2, S-3, and S-4 in $\mathrm{SI})$. Thus, the films appear to have two different morphologies: $\mathrm{CHI} / \mathrm{HA}$ films are constituted of large islets, whereas $\mathrm{CHI} /$ ALG and CHI/CS films have a granular aspect formed by an assembly of smaller particles. The morphologies of the three polysaccharide films built by alternate spraying for a charge ratio of 0.6 for $\mathrm{HA} / \mathrm{CHI}, 0.9$ for $\mathrm{ALG} / \mathrm{CHI}$, and 1.05 for $\mathrm{CS} /$ $\mathrm{CHI}$ are shown in Figure 4d,e,f. Alternate $\mathrm{CHI} / \mathrm{HA}$ films are composed of islets as found for $\mathrm{CHI} / \mathrm{HA}$ films obtained by alternate dipping. ${ }^{30,31}$ Alternate $\mathrm{CHI} / \mathrm{CS}$ films appear granular, as simultaneous sprayed $\mathrm{CHI} / \mathrm{CS}$ films. In the case of the $\mathrm{CHI} /$ ALG system, the films built by alternate spraying appear to be very smooth as in alternate dipping ${ }^{32}$ contrary to films built by simultaneous spraying that show a granular aspect. Polysaccharide films built by alternate spraying process are two or three times smoother than the ones obtained by simultaneous spraying (Table 1). In the simultaneous spraying process, complexes are formed which stick on the surface leading to a rougher film. For the alternate spraying process, polyelectrolyte chains are adsorbed on the surface until the compensation of the electrostatic surface charges is reached. Then, no further material is deposited, the excess of material being removed by drainage. The film growth continues with a smooth aspect of the surface along the whole film buildup. 

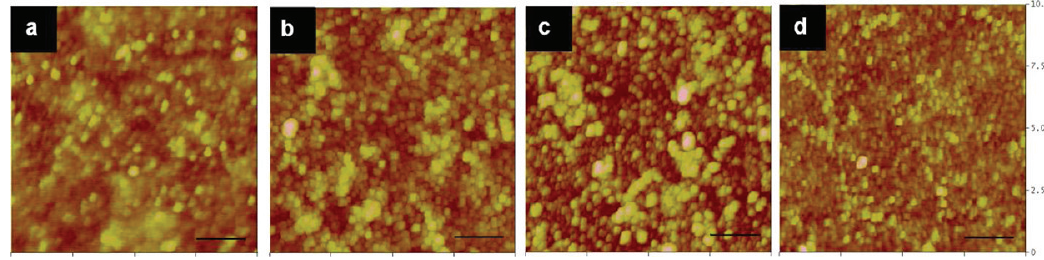

Figure 5. AFM images, obtained in contact mode, of CHI/ALG films built at $150 \mathrm{mM} \mathrm{NaCl}$ and $\mathrm{pH} 4$, at a ALG/CHI spraying ratio of (a) 0.39 , (b) 0.78 , (c) 0.96 , and (d) 3.96 with a CHI spraying rate of $(3.9 \pm 0.2) \times 10^{-4} \mathrm{~mol} / \mathrm{s}$. The $(x, y)$ scale bar represents $2 \mu \mathrm{m}$ and the $z$ scale is $(\mathrm{a}) 20 \mathrm{~nm}$, $(\mathrm{b}, \mathrm{c}) 100 \mathrm{~nm}$, and $(\mathrm{d}) 10 \mathrm{~nm}$.
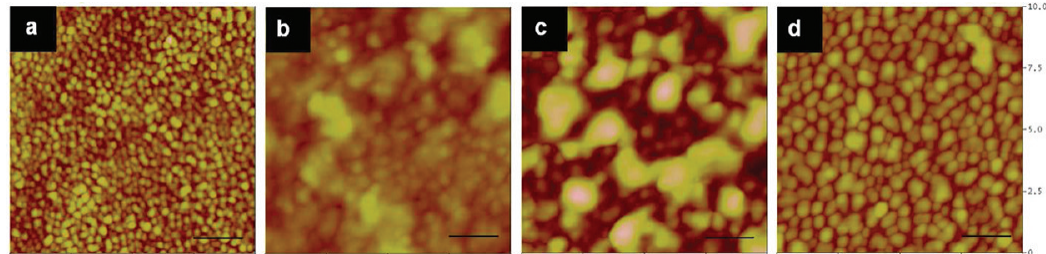

Figure 6. AFM images, obtained in contact mode, of CHI/HA films built at $150 \mathrm{mM} \mathrm{NaCl}$ and $\mathrm{pH} 4$, at a HA/CHI spraying rate ratios of (a) 0.22 , (b) 0.54 , (c) 0.58 , and (d) 1.93 with a CHI spraying rate of $(4.1 \pm 0.4) \times 10^{-4} \mathrm{~mol} / \mathrm{s}$. The $(x, y)$ scale bar is $2 \mu \mathrm{m}$ and the $z$ scale is (a) $10 \mathrm{~nm}$ and $(\mathrm{b}, \mathrm{c}, \mathrm{d}) 80 \mathrm{~nm}$.

We also studied the film morphology for a given cumulative spraying time as a function of the polyanion/CHI spraying charge ratio, with the spraying rate of $\mathrm{CHI}$ being held constant. The evolution of the film morphology of CHI/ALG and CHI/ $\mathrm{HA}$ was studied at different polyanion/CHI molar charge ratio (Figures 5 and 6). The overall morphology of the film does not change with the spraying charge ratios, with the presence of grains for $\mathrm{CHI} / \mathrm{ALG}$ films and islets for $\mathrm{CHI} / \mathrm{HA}$ films. Yet, the size of the particles and islets seems to depend on the polyanion/CHI charge ratio, becoming larger for the optimum charge ratio.

Table 2 summarizes the roughness measured by AFM and the size of the complexes for each polyanion/CHI charge ratio

Table 2. Roughness (RMS), Obtained on $10 \times 10 \mu \mathrm{m}^{2}$ AFM Image, of Polysaccharide Films Obtained by Simultaneous Spraying and Polysaccharide Complexes Size, Obtained by DLS as a Function of the Charge Ratio

$\begin{array}{cccc}\begin{array}{c}\text { polysaccharide } \\ \text { system }\end{array} & \begin{array}{c}\text { polyanion/CHI molar } \\ \text { charge ratio }\end{array} & \begin{array}{c}\text { roughness } \\ (\mathrm{nm})\end{array} & \begin{array}{c}\text { complex size } \\ (\mathrm{nm})\end{array} \\ \mathrm{CHI} / \mathrm{HA} & 0.22 & 1 & 278 \pm 7 \\ & 0.54 & 7 & 304 \pm 9 \\ & 0.58 & 15 & 310 \pm 6 \\ \mathrm{CHI} / \mathrm{ALG} & 1.93 & 7 & 283 \pm 6 \\ & 0.39 & 7 & 223 \pm 2 \\ & 0.78 & 9 & 217 \pm 4 \\ & 0.96 & 13 & 228 \pm 10 \\ & 3.96 & 2 & 170 \pm 2\end{array}$

studied in Figures 5 and 6. For both CHI/ALG and CHI/HA films obtained by simultaneous spraying, we notice an increase of the roughness with the increase in size of the complexes obtained by mixing polysaccharide solutions. This strengthens the hypothesis that for the simultaneous spraying procedure the film buildup depends upon the size of the complexes. We showed that the growth rate and the size of complexes in solution reach their maximum at almost the same polyanion/ $\mathrm{CHI}$ ratio. The buildup of films by simultaneous spraying can thus be described as a stack of polysaccharide complexes on the substrate. This buildup process was described for synthetic polyelectrolytes by Lefort et al. who suggested that a liquid film, that drains along the substrate, is fed with polyelectrolytes. ${ }^{22}$ When the polyanions and polycations enter the liquid film, they form complexes which diffuse toward the substrate/film interface. For small (respectively large) polyanion/CHI charge ratios, there is an excess (respectively deficit) of $\mathrm{CHI}$. Complexes are mainly constituted by few chitosan (respectively polyanion) chains wrapped by several polyanion (respectively chitosan) chains. The small complexes formed appear mainly negatively (respectively positively) charged and repel each other electrostatically rather than interacting attractively. This leads to a lower film growth rate. For the optimum charge ratio on the order of 1 (equivalent molar concentration in polyanion and $\mathrm{CHI}$ ), large polyanion/CHI complexes are formed in the liquid film and are globally neutral with large charge fluctuations (positive and negative patches). One can thus assume that negative patches present on these complexes that diffuse toward the substrate can interact attractively with positive patches present on the other complexes. The constant addition of these large complexes corresponds to the film buildup. This leads to a layer formed by a continuous stack of large complexes. This could be the reason the maximum in film growth rate occurs at polyanion/CHI spraying rate ratios on the order of 1 .

Influence of the Salt Concentration and $\mathrm{pH}$ of Polysaccharide Solutions. We investigated the influence of $\mathrm{pH}$ and salt concentration on the buildup of one polysaccharide system by simultaneous spraying. The influence of these parameters on the alternate buildup of polysaccharide films has already been studied. ${ }^{30,33-36} \mathrm{CHI} / \mathrm{CS}$ films were constructed at different $\mathrm{pH}$ values keeping the salt concentration at $150 \mathrm{mM}$ and at different salt concentrations keeping the $\mathrm{pH}$ value at 4 . Due to the limited solubility of chitosan, tested $\mathrm{pH}$ values are below $\mathrm{pH}$ 6. Compared to a film built at $\mathrm{pH} 4$ and at the same concentration in $\mathrm{NaCl}(150 \mathrm{mM}), \mathrm{CHI} / \mathrm{CS}$ film thickness becomes smallest when the film is built in more acidic $\mathrm{pH}(\mathrm{pH}$ 2) and largest when the $\mathrm{pH}$ is increased to $\mathrm{pH} 6$ (Figure 7a). At $\mathrm{pH} 4$, when the concentration in $\mathrm{NaCl}$ is increased from 0 to 10 $\mathrm{mM}$, there is an increase in the CHI/CS film thickness obtained (Figure $7 \mathrm{~b}$ ). Between 10 and $150 \mathrm{mM}$, the film 

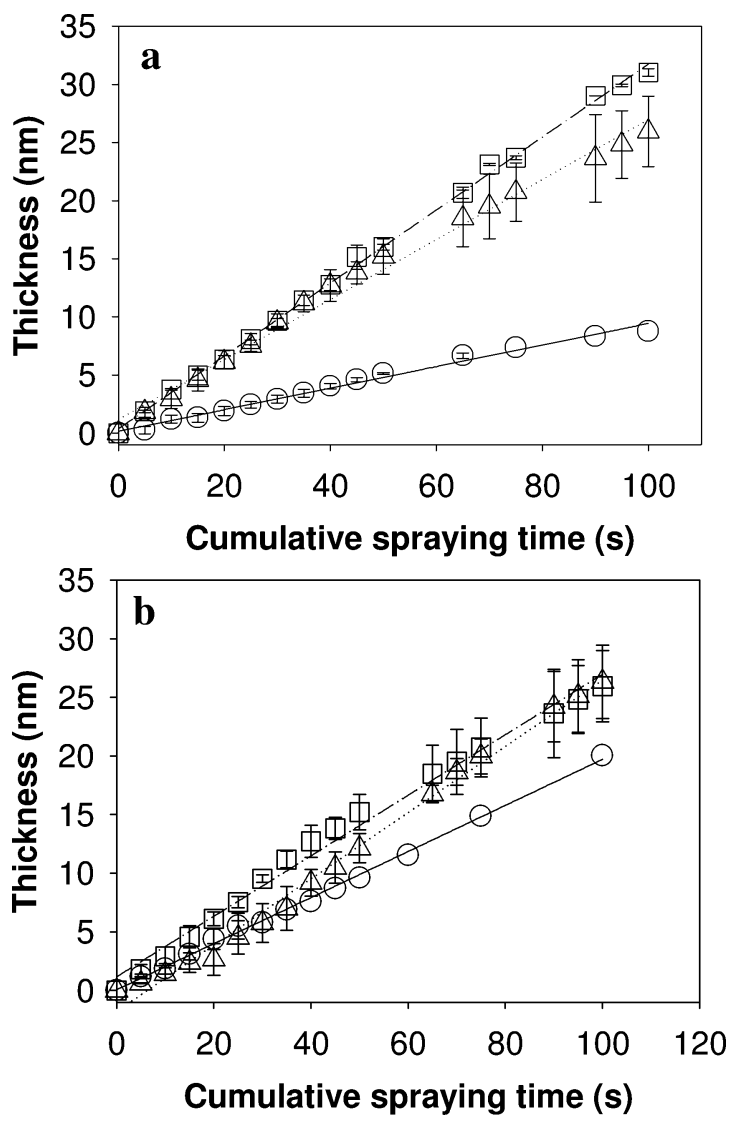

Figure 7. Thickness of CHI/CS films built by simultaneous spraying, with $\mathrm{CHI}$ and $\mathrm{CS}$ solutions prepared (a) at the fixed salt concentration of $150 \mathrm{mM} \mathrm{NaCl}$ at $\mathrm{pH} 2(\mathrm{O}), \mathrm{pH} 4(\triangle)$, and $\mathrm{pH} 6(\square)$ and (b) at $\mathrm{pH} 4$ and $0 \mathrm{mM}(\mathrm{O}), 10 \mathrm{mM}(\triangle)$, and $150 \mathrm{mM} \mathrm{NaCl}(\square)$ as a function of the cumulative spraying time with a $[\mathrm{CS}] /[\mathrm{CHI}]$ molar charge ratio of 2.5 .

growth rate is almost the same. Similar influence of the $\mathrm{pH}^{33-35}$ and the salt ${ }^{30,36}$ concentration was obtained for polysaccharide multilayer films built by the dipping process.

Polysaccharide Films Tested in Cell Culture. Biocompatibility of alternate and simultaneous sprayed polysaccharide films, built at $\mathrm{pH} 4$ in the presence of $150 \mathrm{mM} \mathrm{NaCl}$, was evaluated through the behavior (adhesion, viability, spreading) of HGFs cultured on such substrates. Alternate spraying of $\mathrm{CHI} / \mathrm{HA}, \mathrm{CHI} / \mathrm{ALG}$, and $\mathrm{CHI} / \mathrm{CS}$ systems allows the full coating of the substrate after deposition of, respectively, 23, 9, and 7 bilayers (Figure S-5 in SI). In simultaneous spraying, the three polysaccharide systems coat the substrate totally after a cumulative spraying time of $50 \mathrm{~s}$ (Figures S-2, S-3, and S-4 in SI). To perform cellular tests on homogeneously coated substrates, thicker films were then built by simultaneous spraying with a cumulative spraying time of $125 \mathrm{~s}$ or by the alternate spraying of 25 bilayers. These films were imaged by AFM in the wet state. Concerning alternate and simultaneous $\mathrm{CHI} / \mathrm{HA}$ films, it was difficult to obtain good-quality AFM images in the wet state due to the viscoelasticity of the films as found by Holmes et al. ${ }^{37}$ for films of more than 10 bilayers. It was thus impossible to determine film thickness and roughness of $\mathrm{CHI} / \mathrm{HA}$ in the wet state. CHI/ALG films are granular in the wet state, as in the dry state, with the highest roughness for simultaneously sprayed films compared to alternately sprayed ones (Figure S-6 in SI). CHI/CS films show a different morphology in the wet state than the granular aspect obtained in the dry state. Indeed, alternately and simultaneously sprayed $\mathrm{CHI} / \mathrm{CS}$ films show a foam structure. In the dry and wet states, film thicknesses are comparable for the three systems built at $\mathrm{pH} 4$ in the presence of $150 \mathrm{mM} \mathrm{NaCl}$ (Table S-1 in SI). In contact with a physiological aqueous media $(150 \mathrm{mM} \mathrm{NaCl}, \mathrm{pH}$ 7.4), dry $\mathrm{CHI} / \mathrm{HA}, \mathrm{CHI} / \mathrm{ALG}$, and $\mathrm{CHI} / \mathrm{CS}$ films swell. For both $\mathrm{CHI} / \mathrm{ALG}$ and $\mathrm{CHI} / \mathrm{CS}$ systems, the swelling degree is almost the same for films built by alternate or simultaneous spraying. $\mathrm{CHI} / \mathrm{ALG}$ and $\mathrm{CHI} / \mathrm{CS}$ films swell, respectively, by about 2- and 1.5-fold. This swelling degree is in accordance with those found for polysaccharide multilayer films. ${ }^{38,39}$ The difference in swelling of CHI/ALG and CHI/CS systems could be explained by the difference in ion pairing into the films. ${ }^{26}$ $\mathrm{CHI}$ and ALG are both weak polyelectrolytes; there is then a reduced ion pairing that allows CHI/ALG films to swell. CS is a strong polyelectrolyte and controls the charge density on $\mathrm{CHI}$ increasing ion pairing that compacts $\mathrm{CHI} / \mathrm{CS}$ films and reduces the swelling. The roughness of CHI/ALG films did not change upon swelling (Table S-1 in SI). On the contrary, for the CHI/ CS system, the roughness increases for films obtained by simultaneous spraying and decreases for one obtained in alternate spraying.

Cell Behavior on Polysaccharide Films. HGFs were seeded on the different polysaccharide films, built by the simultaneous spraying with a cumulative spraying time of $125 \mathrm{~s}$ or by the alternate spraying of 25 bilayers. HGFs viability was first assessed by Alamar blue assays, following the mitochondrial activity, for 1, 2, and 7 days (Figure 8). When simultaneous and alternate polysaccharide films are compared, no significant differences in cell viability are found by statistical analysis $(p>0.05$ in each case).

On the first day, a significant reduction of the metabolic cell activity was observed when HGFs were cultivated on $\mathrm{CHI} /$ $\mathrm{ALG}$ and $\mathrm{CHI} / \mathrm{CS}$ systems compared to glass substrate. On the contrary, no significant differences were observed for $\mathrm{CHI} / \mathrm{HA}$ systems compared to glass. After one week, significantly smaller metabolic activity was still found on both $\mathrm{CHI} / \mathrm{ALG}$ and $\mathrm{CHI} /$

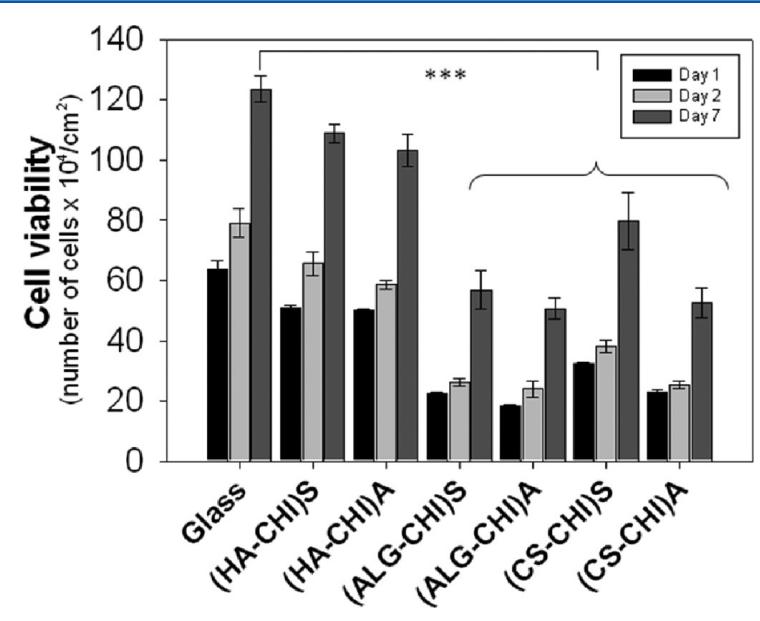

Figure 8. Viability of HGFs, evaluated by metabolic activity of cells, on $\mathrm{CHI} / \mathrm{HA}, \mathrm{CHI} / \mathrm{ALG}$, and $\mathrm{CHI} / \mathrm{CS}$ films built on glass substrates by simultaneous spraying, with a cumulative spraying time of $125 \mathrm{~s}$, denoted (polyanion/CHI)S, or by alternate spraying of 25 bilayers denoted (polyanion/CHI)A. Cell viability was determined by Alamar Blue assays after 1,2 , and 7 days of culture. The values represent the mean and the standard deviation of three independent experiments performed in triplicate. Mean values at Day 7 were compared to bare substrate with one-way ANOVA test, with $* * *$ meaning $p<0.001$. 
CS systems compared to the glass substrate $(p<0.001$; Figure 8 ). This is probably a consequence of the weak initial adhesion of cells. On $\mathrm{CHI} / \mathrm{HA}$ films, either obtained by alternate or simultaneous spraying procedures, HGFs activities were only slightly smaller than those found on a glass substrate.

We analyzed the biocompatibility of films by a complementary assay based on cell spreading via cytoskeleton arrangement. Cells are able to sense their microenvironment and to respond by adjusting the organization of their cytoskeleton. After 12 days of culture, a confluent layer with a typical fibroblastic cell shape and with polymerized F-actin fibers lying parallel to one other were observed on alternate and simultaneous $\mathrm{CHI} / \mathrm{HA}$ films (Figure 9a,d). For CHI/ALG and

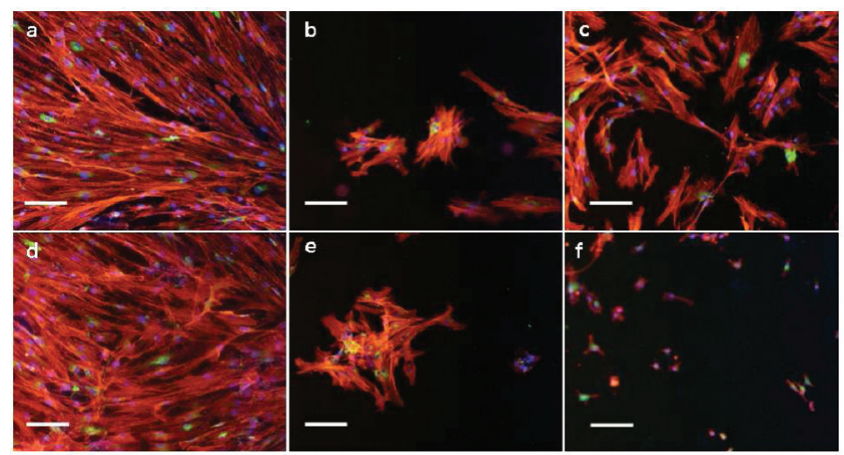

Figure 9. Immunolabeling of HGFs after 12 days of culture on (a) (HA/CHI)S, (b) (ALG/CHI)S, and (c) (CS/CHI)S films built by simultaneous spraying with a cumulative spraying time of $125 \mathrm{~s}$ and (d) (HA/CHI)A, (e) (ALG/CHI)A, and (f) (CS/CHI)A films built by alternate spraying of 25 bilayers. The cytoskeleton was visualized by actin filament staining with phalloidin (red labeling), and COL1 (green labeling) was detected by immunochemistry with Blue nucleus counterstaining of HGFs. The scale bar represents $100 \mu \mathrm{m}$.

$\mathrm{CHI} / \mathrm{CS}$ systems, no confluent cell layer was observed for both films obtained by simultaneous and alternate spraying (Figure $9 b, c$ and e,f). Indeed, cells appear less elongated and have a peripheral actin distribution. Previously published data showed a weak adhesion of SaOs-2 human osteoblast-like cell line and L929 human fibroblast-like cell line on CHI/ALG multilayers. ${ }^{40}$ $\mathrm{CHI} / \mathrm{CS}$ multilayer films, used to functionalize poly(ethylene terephthalate) prosthesis, showed a good human endothelial cell adhesion but with a decrease of their antithrombogenic properties. $^{27}$ In the case of CHI/CS coatings, better HGFs adhesion seemed to occur on simultaneous sprayed films compared to the alternate ones (Figure 9c,f). This effect was also observed with the Alamar blue assay at Day 7, but the significance of the results remains in the limit of the statistical tests $(p=0.051)$. For a given polysaccharide system, the spraying process used to build the film leads to a significant difference in film roughness, i.e., simultaneously sprayed films have a higher roughness than alternately sprayed ones (Table S1 in SI). However, cell viability and spreading are quite similar for a given polysaccharide system whatever the spraying process used. In contrary, the polysaccharide type used to build the films seems to play a determinant role in cell viability. Indeed, the results highlight the better biocompatibility of $\mathrm{CHI} / \mathrm{HA}$ films compared to $\mathrm{CHI} / \mathrm{ALG}$ and $\mathrm{CHI} / \mathrm{CS}$ films.

We then checked by immunocytochemistry the preservation of HGFs function, when cultivated on CHI/HA films, through collagen type I (COL1) synthesis with perinuclear localization. $^{41}$ Indeed, COL1 is the main component of the extracellular matrix produced by fibroblasts. HGFs cultured on alternate and simultaneous $\mathrm{CHI} / \mathrm{HA}$ films remained positive to COL1 (green labeling) with a peripheral distribution (Figure 9) comparable to the glass substrate (Figure S-7 in SI). Various studies reported on the same $\mathrm{CHI} / \mathrm{HA}$ multilayer film a weak adhesion of platelets and leucocytes, ${ }^{15}$ chondrosacroma, ${ }^{30}$ MC3T3 preosteoblasts, ${ }^{42}$ bone marrow derived mesenchymal stem cells, ${ }^{43}$ BALB/c 3T3 fibroblast cell line, ${ }^{44}$ and MC3T3-E1 osteoblasts cell line. ${ }^{45}$ For these authors, the low cell adhesion and proliferation on the $\mathrm{CHI} / \mathrm{HA}$ film is mainly due to the mechanical properties of the film which is not rigid enough. These results are in contrast with our findings on HGFs.

From a chemical point of view, HA is a ligand for CD44, a cell surface receptor found on several types of mammalian cells. Cells bind to substrates via adhesion molecules whose intracellular domains are connected to the cytoskeleton. The reorganization of the cytoskeleton has been associated with increased expression and receptor clustering of the standard form of CD 44. ${ }^{46}$ Vasconcellos et al. showed that the interaction of $\mathrm{CH} 27$ B lymphocytes, nonadhesive cells, with the $\mathrm{CHI} / \mathrm{HA}$ film was mediated via CD44 receptors. ${ }^{28}$ So, we postulated that the good CHI/HA biocompatibility is due to CD44 and HA binding. CD44 labeling showed the formation of clusters at the membrane of HGFs only when cultivated on alternately or simultaneously sprayed CHI/HA films (Figure 10). So the
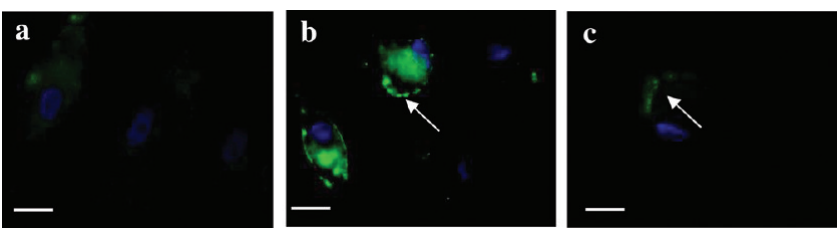

Figure 10. Detection of CD44 receptor (green labeling) and blue nucleus counterstaining of HGFs after one day of culture on (a) glass substrate, (b) (HA/CHI)S film built by simultaneous spraying with a cumulative spraying time of $125 \mathrm{~s}$, and (c) (HA/CHI)A film built by alternate spraying of 25 bilayers. The scale bar represents $20 \mu \mathrm{m}$. Arrows correspond to formation of clusters of CD44 receptors on the membrane of fibroblasts.

HGFs function and adaptive behavior on CHI/HA films seem to be mediated via CD44 receptor. The presence of $\mathrm{HA}$, as a component of alternate or simultaneous films, seems to play a major role in HGFs adhesion and spreading on polysaccharide films.

\section{CONCLUSION}

Simultaneous and alternate spraying procedures of two polysaccharide solutions onto a substrate held vertically with a vertical and rotational movement lead to the formation of homogeneous surface coatings. We investigated the simultaneous spraying of $\mathrm{CHI}$ with $\mathrm{HA}, \mathrm{ALG}$, and CS solutions leading to the formation of a film constituted by $\mathrm{CHI} /$ polyanion complexes. The thickness of polysaccharide films increases linearly with the cumulative spraying time. The growth rate of simultaneously sprayed films depends highly upon the polyanion/CHI molar charge ratios and reaches a maximum for precise charge ratios. These values are very close to those corresponding to the maximal size of the complexes. This observation strengthens the hypothesis that the coatings are formed by an accumulation of complexes on the solid surfaces. We confirmed that the film morphology, investigated by AFM, is independent of the spraying rate ratios and the 
roughness of the film is higher for simultaneously than for alternately sprayed films. The biocompatibility of the coatings was tested by HGFs behavior. The $\mathrm{CHI} / \mathrm{HA}$ system, whatever the deposition procedure (simultaneous or alternate spraying conditions), appeared as a promising surface coating for biomedical applications. From an industrial point of view, the alternate spraying of polysaccharides seems to be less reagentconsuming but more time-consuming than the simultaneous spraying. Simultaneous spraying of interacting polysaccharides is of large interest for fast preparation of surface coatings in the range of a few nanometers up to several micrometers. These coatings may be further biofunctionalized for bioengineering applications.

\section{ASSOCIATED CONTENT}

\section{S Supporting Information}

Buildup of polysaccharide films obtained by alternate spraying; AFM topography and line profiles of $\mathrm{CHI} / \mathrm{HA}, \mathrm{CHI} / \mathrm{ALG}$, and $\mathrm{CHI} / \mathrm{CS}$ films built by simultaneous spraying; AFM topography and line profiles of $\mathrm{CHI} / \mathrm{HA}, \mathrm{CHI} / \mathrm{ALG}$, and CHI/CS films built by alternate spraying; thickness and roughness, in wet state, of polysaccharide films used for cellular tests; immunocytochemistry of HGFs cultured on bare glass substrate. This material is available free of charge via the Internet at http://pubs.acs.org.

\section{AUTHOR INFORMATION}

\section{Corresponding Author}

*E-mail: fouzia.boulmedais@ics-cnrs.unistra.fr, tel: +33 (0) 3 884141 60, fax: +33 (0) 388414000 .

\section{Notes}

The authors declare no competing financial interest.

\section{ACKNOWLEDGMENTS}

Bernard Senger is acknowledged for his help in statistical analysis. G. C. was supported by a "BDI" doctoral fellowship of the Centre National de la Recherche Scientifique and the Région Alsace. "Jeunes Chercheurs du PMNA 2009" is acknowledged for financial support.

\section{REFERENCES}

(1) Boddohi, S.; Kipper, M. J. Engineering Nanoassemblies of Polysaccharides. Adv. Mater. 2010, 22, 2998-3016.

(2) Cooper, S. L.; Peppas, N. A. Biomaterials, interfacial phenomena and applications; American Chemical Society: Washington, DC, 1982; p 539.

(3) Ratner, B., Biomedical applications of synthetic polymers. In Comprehensive Polymer Science, Aggarwal, S., Ed.; Pergamon Press: New York, 1989; pp 201-247.

(4) Gombotz, W. R.; Hoffman, A. S. Gas-Discharge Techniques for Biomaterial Modification. Crit. Rev. Biocompat. 1987, 4, 1-42.

(5) Ratner, B. D. New Ideas in Biomaterials Science - a Path to Engineered Biomaterials. J. Biomed. Mater. Res. 1993, 27, 837-850.

(6) Ratner, B. D.; Chilkoti, A.; López, G. P. Plasma deposition and treatment for biomaterial applications. In Plasma Deposition, Treatment and Etching of Polymers, D'Agostino, R., Ed.; Academic Press: San Diego, 1990; pp 463-516.

(7) Decher, G.; Hong, J. D.; Schmitt, J. Buildup of ultrathin multilayer films by a self-assembly process. Consecutively alternating adsorption of anionic and cationic polyeletrolytes on charges surface. Thin Solid Films 1992, 210/211, 831-835.

(8) Morra, M. Engineering of biomaterials surfaces by hyaluronan. Biomacromolecules 2005, 6, 1205-1223.
(9) Zhou, J.; Romero, G.; Rojas, E.; Ma, L.; Moya, S.; Gao, C. Y. Layer by layer chitosan/alginate coatings on poly(lactide-co-glycolide) nanoparticles for antifouling protection and Folic acid binding to achieve selective cell targeting. J. Colloid Interface Sci. 2010, 345, 241247.

(10) Richert, L.; Boulmedais, F.; Lavalle, P.; Mutterer, J.; Ferreux, E.; Decher, G.; Schaaf, P.; Voegel, J.-C.; Picart, C. Improvement of stability and cell adhesion properties of polyelectrolyte multilayer films by chemical cross-linking. Biomacromolecules 2004, 5, 284-294.

(11) Schneider, A.; Francius, G.; Obeid, R.; Schwinté, P.; Hemmerlé, J.; Frisch, B.; Schaaf, P.; Voegel, J.-C.; Senger, B.; Picart, C. Polyelectrolyte multilayers with a tunable Young's modulus: Influence of film stiffness on cell adhesion. Langmuir 2006, 22, 1193-1200.

(12) Boulmedais, F.; Frisch, B.; Etienne, O.; Lavalle, P.; Picart, C.; Ogier, J.; Voegel, J.-C.; Schaaf, P.; Egles, C. Polyelectrolyte multilayer films with pegylated polypeptides as a new type of anti-microbial protection for biomaterials. Biomaterials 2004, 25, 2003-2011.

(13) Bratskaya, S.; Marinin, D.; Simon, F.; Synytska, A.; Zschoche, S.; Busscher, H. J.; Jager, D.; van der Mei, H. C. Adhesion and viability of two enterococcal strains on covalently grafted chitosan and chitosan/ kappa-carrageenan multilayers. Biomacromolecules 2007, 8, 29602968.

(14) Liu, M.; Yue, X. L.; Dai, Z. F.; Xing, L.; Ma, F.; Ren, N. Q. Stabilized hemocompatible coating of nitinol devices based on photocross-linked Alginate/Heparin multilayer. Langmuir 2007, 23, 93789385.

(15) Thierry, B.; Winnik, F. M.; Merhi, Y.; Silver, J.; Tabrizian, M. Bioactive coatings of endovascular stents based on polyelectrolyte multilayers. Biomacromolecules 2003, 4, 1564-1571.

(16) Crouzier, T.; Szarpak, A.; Boudou, T.; Auzely-Velty, R.; Picart, C. Polysaccharide-Blend Multi layers Containing Hyaluronan and Heparin as a Delivery System for rhBMP-2. Small 2010, 6, 651-662.

(17) Almodovar, J.; Bacon, S.; Gogolski, J.; Kisiday, J. D.; Kipper, M. J. Polysaccharide-Based Polyelectrolyte Multi layer Surface Coatings can Enhance Mesenchymal Stem Cell Response to Adsorbed Growth Factors. Biomacromolecules 2010, 11, 2629-2639.

(18) Schlenoff, J. B.; Dubas, S. T.; Farhat, T. Sprayed polyelectrolyte multilayers. Langmuir 2000, 16, 9968-9969.

(19) Krogman, K. C.; Lowery, J. L.; Zacharia, N. S.; Rutledge, G. C.; Hammond, P. T. Spraying asymmetry into functional membranes layer-by-layer. Nat. Mater. 2009, 8, 512-518.

(20) Porcel, C.; Izquierdo, A.; Ball, V.; Decher, G.; Voegel, J.-C.; Schaaf, P. Ultrathin coatings and (poly(glutamic acid)/polyallylamine) films deposited by continuous and simultaneous spraying. Langmuir 2005, 21, 800-802.

(21) Schaaf, P.; Voegel, J.-C.; Jierry, L.; Boulmedais, F. Spray-Assisted Polyelectrolyte Multilayer Buildup: from Step-by-Step to Single-Step Polyelectrolyte Film Constructions. Adv. Mater. 2012, 24, 1001-1016.

(22) Lefort, M.; Boulmedais, F.; Jierry, L.; Gonthier, E.; Voegel, J.-C.; Hemmerlé, J.; Lavalle, P.; Ponche, A.; Schaaf, P. Simultaneous Spray Coating of Interacting Species: General Rules Governing the Poly(styrene sulfonate)/Poly(allylamine) System. Langmuir 2011, 27, 4653-4660.

(23) Lefort, M.; Popa, G.; Seyrek, E.; Szamocki, R.; Felix, O.; Hemmerlé, J.; Vidal, L.; Voegel, J.-C.; Boulmedais, F.; Decher, G.; Schaaf, P. Spray-On Organic/Inorganic Films: A General Method for the Formation of Functional Nano- to Microscale Coatings. Angew. Chem., Int. Ed 2010, 49, 10110-10113.

(24) Page, B.; Page, M.; Noel, C. A New Fluorometric Assay for Cytotoxicity Measurements in-Vitro. Int. J. Oncol. 1993, 3, 473-476.

(25) Voytik-Harbin, S. L.; Brightman, A. O.; Waisner, B.; Lamar, C. H.; Badylak, S. F. Application and evaluation of the alamarBlue assay for cell growth and survival of fibroblasts In Vitro. Cell. Dev-An 1998, $34,239-246$.

(26) Almodovar, J.; Place, L. W.; Gogolski, J.; Erickson, K.; Kipper, M. J. Layer-by-Layer Assembly of Polysaccharide-Based Polyelectrolyte Multilayers: A Spectroscopic Study of Hydrophilicity, Composition, and Ion Pairing. Biomacromolecules 2011, 12, 2755-2765. 
(27) Liu, Y. X.; He, T.; Gao, C. Y. Surface modification of poly(ethylene terephthalate) via hydrolysis and layer-by-layer assembly of chitosan and chondroitin sulfate to construct cytocompatible layer for human endothelial cells. Colloids Surf., B 2005, 46, 117-126.

(28) Vasconcellos, F. C.; Swiston, A. J.; Beppu, M. M.; Cohen, R. E.; Rubner, M. F. Bioactive Polyelectrolyte Multilayers: Hyaluronic Acid Mediated B Lymphocyte Adhesion. Biomacromolecules 2010, 11, 2407-2414.

(29) Schneider, A.; Richert, L.; Francius, G.; Voegel, J.-C.; Picart, C. Elasticity, biodegradability and cell adhesive properties of chitosan/ hyaluronan multilayer films. Biomed. Mater. 2007, 2, S45-S51.

(30) Richert, L.; Lavalle, P.; Payan, E.; Shu, X. Z.; Prestwich, G. D.; Stoltz, J.-F.; Schaaf, P.; Voegel, J.-C.; Picart, C. Layer by layer buildup of polysaccharide films: Physical chemistry and cellular adhesion aspects. Langmuir 2004, 20, 448-458.

(31) Kujawa, P.; Moraille, P.; Sanchez, J.; Badia, A.; Winnik, F. M. Effect of molecular weight on the exponential growth and morphology of hyaluronan/chitosan multilayers: A surface plasmon resonance spectroscopy and atomic force microscopy investigation. J. Am. Chem. Soc. 2005, 127, 9224-9234.

(32) Marken, E.; Maurstad, G.; Stokke, B. T. Quantitative analysis of atomic force microscopy topographs of biopolymer multilayers: Surface structure and polymer assembly modes. Thin Solid Films 2008, 516, 7770-7776.

(33) Fu, J. H.; Ji, J.; Yuan, W. Y.; Shen, J. C. Construction of antiadhesive and antibacterial multilayer films via layer-by-layer assembly of heparin and chitosan. Biomaterials 2005, 26, 6684-6692.

(34) Boddohi, S.; Killingsworth, C. E.; Kipper, M. J. Polyelectrolyte multilayer assembly as a function of $\mathrm{pH}$ and ionic strength using the polysaccharides chitosan and heparin. Biomacromolecules 2008, 9, 2021-2028.

(35) Lundin, M.; Solaqa, F.; Thormann, E.; Macakova, L.; Blomberg, E. Layer-by-Layer Assemblies of Chitosan and Heparin: Effect of Solution Ionic Strength and pH. Langmuir 2011, 27, 7537-7548.

(36) Lundin, M.; Blomberg, E.; Tilton, R. D. Polymer Dynamics in Layer-by-Layer Assemblies of Chitosan and Heparin. Langmuir 2010, 26, 3242-3251.

(37) Holmes, C. A.; Tabrizian, M. Enhanced MC3T3 preosteoblast viability and adhesion on polyelectrolyte multilayer films composed of glycol-modified chitosan and hyaluronic acid. J. Biomed. Mater. Res. A 2012, 100A, 518-526.

(38) Burke, S. E.; Barrett, C. J. pH-responsive properties of multilayered poly(L-lysine)/hyaluronic acid surfaces. Biomacromolecules 2003, 4, 1773-1783.

(39) Ferrer, M. C. C.; Yang, S.; Eckmann, D. M.; Composto, R. J. Creating Biomimetic Polymeric Surfaces by Photochemical Attachment and Patterning of Dextran. Langmuir 2010, 26, 14126-14134.

(40) Martins, G. V.; Merino, E. G.; Mano, J. F.; Alves, N. M. Crosslink Effect and Albumin Adsorption onto Chitosan/Alginate Multilayered Systems: An in situ QCM-D Study. Macromol. Biosci. 2010, 10, 1444-1455.

(41) Chassepot, A.; Gao, L.; Nguyen, I.; Dochter, A.; Fioretti, F.; Menu, P.; Kerdjoudj, H.; Baehr, C.; Schaaf, P.; Voegel, J.-C.; Boulmedais, F.; Frisch, B.; Ogier, J. Chemically Detachable Polyelectrolyte Multilayer Platform for Cell Sheet Engineering. Chem. Mater. 2012, 24, 930-937.

(42) Hillberg, A. L.; Holmes, C. A.; Tabrizian, M. Effect of genipin cross-linking on the cellular adhesion properties of layer-by-layer assembled polyelectrolyte films. Biomaterials 2009, 30, 4463-4470.

(43) Liu, Z. M.; Gu, Q. Y.; Xu, Z. K.; Groth, T. Synergistic Effect of Polyelectrolyte Multilayers and Osteogenic Growth Medium on Differentiation of Human Mesenchymal Stem Cells. Macromol. Biosci. 2010, 10, 1043-1054.

(44) Larkin, A. L.; Davis, R. M.; Rajagopalan, P. Biocompatible, Detachable, and Free-Standing Polyelectrolyte Multilayer Films. Biomacromolecules 2010, 11, 2788-2796.

(45) Chua, P. H.; Neoh, K. G.; Kang, E. T.; Wang, W. Surface functionalization of titanium with hyaluronic acid/chitosan polyelec- trolyte multilayers and RGD for promoting osteoblast functions and inhibiting bacterial adhesion. Biomaterials 2008, 29, 1412-1421.

(46) Pure, E.; Assoian, R. K. Rheostatic signaling by CD44 and hyaluronan. Cell. Signal. 2009, 21, 651-655. 